\title{
Does the Belgian diabetes type 2 care trajectory improve quality of care for diabetes patients?
}

Viviane F. A. Van Casteren ${ }^{1 *}$, Nathalie H. E. Bossuyt ${ }^{1}$, Sarah J. S. Moreels ${ }^{1}$, Geert Goderis ${ }^{2,3}$, Katrien Vanthomme ${ }^{4}$, Johan Wens ${ }^{5}$ and Etienne W De Clercq ${ }^{6}$

\begin{abstract}
Background: The Belgian care trajectory (CT) for diabetes mellitus type 2 (T2DM), implemented in September 2009, aims at providing integrated, evidence-based, multidisciplinary patient- centred care, based on the chronic care model. The research project ACHIL (Ambulatory Care Health Information Laboratory) studied the adherence of CT patients, in the early phases of CT programme implementation, with CT obligations, their uptake of incentives for self-management, whether the CT programme was targeting the appropriate group of patients, how care processes for these patients evolved over time and whether $\mathrm{CT}$ start led to better quality in the processes and outcomes of care.

Methods: This observational study took place in the period 2006-2011 and covered T2DM patients who started a CT between 01/09/2009 and 31/12/2011.

Four data sources were used: outcome data, from electronic patient records (EPRs) on all CT patients, provided by general practitioners (GPs); reimbursement process data on all CT patients and clinically comparable patients; and data from a sample of CT patients and clinically comparable patients from an EPR-based regional GP network and a paper-based national GP network, respectively.

Through multilevel analysis of cross-sectional and longitudinal data, the effect of CT inclusion on processes and outcome was estimated, controlling for potential confounders.

Results: By the end of 2011, data on 18,250 CT patients had been collected. Approximately $50 \%$ of these CT patients had received reimbursement for a glucometer and nearly $60 \%$ had had at least one encounter with a diabetes educator. The CT programme recruited T2DM patients who had been difficult to control in the past. In the years prior to CT start, there had been a gradual improvement in the follow up of these patients. Moreover, compared to non- $\mathrm{CT}$ patients, the proportion of $\mathrm{CT}$ patients adhering to the recommended frequency for monitoring of parameters, such as $\mathrm{HbA1C}$, increased significantly around CT start. Some data sources, albeit not all, suggested there had been an improvement in certain outcomes, such as $\mathrm{HbA1c}$, after $\mathrm{CT}$ inclusion.
\end{abstract}

Conclusions: According to this study, CT enrolment is associated with better quality of care processes compared to non-CT patients. This improvement was found in several of the data sources used in this study. However, results on outcome parameters remain inconclusive.

Keywords: Type 2 diabetes mellitus, Quality of care, Primary care, Chronic disease management

\footnotetext{
*Correspondence: viviane.vancasteren@wiv-isp.be

'Scientific Institute of Public Health, Operational Direction Public Health and

Surveillance, J. Wytsmanstreet 14, 1050 Brussels, Belgium

Full list of author information is available at the end of the article
} 


\section{Background}

The Belgian health care system is based on a compulsory insurance system, which covers $99 \%$ of the population for a wide range of health conditions. The health system focuses mainly on acute diseases and hospital care. Feefor-service payments apply to most ambulatory and medical services, delivered by self-employed health professionals. Patients are free to choose their health care professional. General practitioners (GPs) have no formal gate-keeping function and patients have direct access to specialists and emergency services. Nevertheless, the national Health Interview Survey (HIS) of 2013 showed that a large majority of the population ( $94 \%$ ) has a regular GP, and that the mean number of contacts per year is 3.9 (self-reported by the patient) [1]. Moreover, a number of decisions were taken in past years to reassess and strengthen primary care. Among these, the Global Medical File (GMF) was established in 1999 to increase the availability of medical, social and administrative patient information and access to such information. The GP holds the GMF with the patient's consent and shares relevant information with other providers responsible for the patient. Only one GP can hold the patient's file.

Primary care is dominated by single-handed, selfemployed practices for general practice, physiotherapy, speech therapy and so on, with only a limited number of integrated primary care centres. The number of such practices is growing, although there is still only a small minority of people affiliated to them.

As in most other European countries, the Belgian health care system is struggling with changing health care needs. Higher life expectancy is associated with an increasing prevalence of chronic diseases such as diabetes mellitus type 2 (T2DM), which has a growing impact on healthcare delivery and costs.

Up to 2009, the main government regulation in diabetes care was the so-called diabetes convention " 786 ". Since 1988, Belgian multidisciplinary hospital-based diabetic centres (over 100) can conclude a diabetes convention with the National Institute for Health and Disability Insurance (NIHDI). This convention aims at providing a self-regulation programme for people with diabetes. Initially, this convention targeted only type 1 diabetes mellitus (T1DM) and later on, the target public also included the growing number of patients with T2DM with at least 2 insulin injections a day. When the latter adhere to such a diabetic centre, they are followed up by a multidisciplinary diabetes team led by an endocrinologist. They receive reimbursement of diabetes education and self-monitoring materials and get access to specialised advice, e.g. podiatry and cardiology. According to the number of insulin injections a day and glycaemic self-control measurements, various subcategories of the diabetes convention exist, e.g. convention 3A concerns patients with two or more insulin injections a day and more than 30 glycaemic measurements a month. In 2001 a quality improvement initiative, called IQED and run by the Scientific Institute of Public Health, was installed [2, 3]. Since 2005 a diabetic foot convention exists between the NIHDI and over 30 diabetic multidisciplinary foot clinics, organised in larger hospitals, focusing on prevention and treatment of complex diabetic foot problems. A quality improvement initiative, the so called IQED Foot project is linked to this convention [4].

With the growing number of patients with T2DM, including those on insulin therapy, the diabetes convention more and more suffered from its historical weaknesses. First, the programme only targets diabetes patients with insulin therapy. All other diabetics, according to the HIS 2013 approximately $72 \%$ of the diabetic population [5], were excluded from this care programme and had to make considerable contributions for dietetic and podiatric services and self-monitoring materials. Even a subpopulation of insulin-treated diabetes patients, those on one daily injection were excluded from this care programme as well as from the reimbursement of the necessary blood glucose monitoring material.

Further on, the diabetes convention also resulted in most diabetes patients on insulin being treated in secondary care, while many of those patients (especially those who need 2 doses of insulin a day) could be cared in primary care with the pivotal role of the GP. Moreover, insulin therapy being monopolized in diabetes centres, GPs risked to lose the necessary competences to initiate and follow-up insulin therapy. On the other hand, with the growing number of diabetes patients, the convention centres risked to be overwhelmed.

For all these reasons, there was an urgent need to reorganise the managed care for people with diabetes. Within this new system the diabetes convention could focus on diabetics with complex insulin schemes or severe complications.

However, Goderis et al. found in 2006 a better overall metabolic control in T2DM patients followed up in diabetic convention centres (with more structured care compared to primary care), compared to diabetics followed up in primary care [6].

On the other hand, Goderis et al. illustrated that a multifaceted diabetes programme in general practice with various interventions, such as a clear treatment protocol, postgraduate education of GPs, case-coaching by an endocrinologist, benchmarking feedback and possibility of patient's referral for diabetes education free of charge, substantially improved quality of care and major diabetesrelated patient outcomes [7].

In 2006, the Belgian Health Care Knowledge Centre (KCE) recommended a new organisation of the care for the rapidly increasing T2DM patient population with a shift 
from symptom oriented treatment to proactive integrated and patient oriented care. This new organisation of care includes, for example, involvement of a multidisciplinary team, empowerment of the patient, patient education, a central coordinating role for the GP, a possible coaching role for the endocrinologist, and a quality of care monitoring system [8].

The reflection on the need to change the present health care system for T2DM and by extension for other chronic diseases, was not only made in Belgium. In recent years, new chronic care programmes were implemented and evaluated in many other countries in and outside Europe [9-20]. Most approaches tend to be disease-specific, with T2DM most typically targeted. A common finding in the evaluation is that the programmes are associated with better diabetes care processes, but conclusions about their impact on outcomes such as clinical parameters (e.g. blood pressure, blood lipids, HbA1c), hospital admissions and mortality vary from one study to another and are not conclusive.

All these care programmes are to a large extent inspired by Wagner's chronic care model (CCM).

For more than a decade, this CCM has been used to transform daily care for patients with chronic illnesses from an acute, reactive approach to a proactive, planned approach [21-25].

In Belgium, the care trajectory (CT) for T2DM was introduced by the NIHDI in 2009. This CT approach can be considered as the first phase of implementation of Wagner's CCM in Belgium. First phase meaning that the focus is on a specific disease and even on a limited subset of T2DM patients and not on chronic diseases in general. The Belgian T2DM-CT aims to improve delivery of care and health outcomes by reinforcing proactively planned, integrated, evidence-based, multidisciplinary care for empowered patients [26]. It is focusing on patients in an earlier phase of their disease, in contrast to diabetes convention patients, who are often in a more advanced stage of diabetes. CT-eligible patients include T2DM patients on one or two insulin injections or GLP-analogues and those experiencing insufficient regulation with maximum oral antidiabetic treatment excluding pregnant women and T1DM patients [26].

The CT is defined by a four-year renewable contract between patient, GP and specialist. This contract aims to support the interaction between the three parties, each of whom has to respect certain rules in order to receive incentives. For example, after signing a CT contract, a patient is reimbursed in full for encounters with his or her GP and specialist [26]. He or she receives material for self-monitoring, has improved access to a diabetes educator/dietician and podiatrist, and receives partial reimbursement for these visits. On the other hand, the CT contract also stipulates that the patient must have at least two encounters a year with his or her GP and one encounter a year with the specialist.

Within the multidisciplinary care environment, the GP acts as the coordinator of the medical management according to an individualised care plan. The specialist's role is to keep the GP's knowledge up-to-date and coach him or her in relation to individual patients. In order to facilitate multidisciplinary care, new local structures, known as "local multidisciplinary networks" (LMN), were set up with the financial support of the NIHDI. In these networks, a new care manager function, the care trajectory promoter, was introduced [26].

Before including the patient in a T2DM-CT programme, the GP can eventually start a diabetes education and selfmanagement programme, in which only the GP provides diabetes education and the patient receives free material for self-monitoring of blood glucose [26]. There is no multidisciplinary approach in this latter care programme. Inclusion criteria for the patient are being treated with either injectable incretinemimetics or one insuline injection per day. If after one year of inclusion in this programme the patient's HbA1c level is not $<7.5 \%$, the GP proposes the patient to join the T2DM-CT care programme.

There is some overlap between the diabetes convention $3 \mathrm{~A}$ and the T2DM-CT for patients on two insulin injections per day. Convention $3 \mathrm{~A}$ patients can stay in the convention or move to a T2DM-CT, but once in a T2DM-CT, they are not allowed to switch to the convention $3 \mathrm{~A}$ [26].

The research project ACHIL (Ambulatory Care Health Information Laboratory) assessed the adherence of CT patients, in the early phases of CT programme implementation, to the CT rules; their uptake of incentives for self-management; whether the CT programme was targeting the appropriate group of patients; how care processes for these patients evolved over time; and whether inclusion in the CT led to better quality in the processes and outcomes of care. Both crude effectiveness (proportion of patients meeting a target value) and comparative effectiveness (comparison with a control group or over time) were assessed. With regard to the latter, various groups of T2DM patients were used: T2DM patients in a care programme on diabetes education and self-management, diabetes convention 3A patients on two insulin injections a day, CT-eligible T2DM patients not included in a CT and T2DM patients in no specifically dedicated care programme.

This article describes an extract of the ACHIL project's T2DM-CT-related research objectives, the approach to meeting these objectives, and some general results from the early phases of T2DM-CT implementation. More details on the methodology and some specific results are reported elsewhere [27-31]. 


\section{Methods}

Research domains, research questions and quality-related parameters

Table 1 gives an overview of the research domains and (quality-related) parameters considered in this article, together with the studied target frequency of measurement and target outcome value. The research questions on quality of care of diabetes were selected in accordance to a 2006 report of the Belgian KCE on quality of T2DM care [8] and the follow-up plan for the care trajectory diabetes, developed by the National Council for Quality Promotion and based upon the national recommendation for good medical practice [32]. The KCE report classified relevant guidelines and the resulting evidence based quality indicators (at micro level) from international reference literature within major areas of diabetes care. Appropriate target values to these quality indicators have been assigned. The study method was based on a study evaluating the diabetes convention carried out by the Intermutualistic Agency [33] and on a study evaluating a diabetes care quality improvement programme for general practitioners that was carried out by the KU Leuven and the Universiteit Antwerpen [7, 34].

\section{Data sources}

Four data sources were selected in order to answer the research questions. Detailed information about the four data sources is reported elsewhere [35].

\section{Central pillar}

This data source was the result of the compulsory recording of four parameters (HbA1c, LDL cholesterol, blood pressure and $\mathrm{BMI}$ ), with at least one value per parameter, by Belgian GPs for all T2DM-CT patients (see Table 1). Data were entered by GPs using a secure web application, either manually or with the help of automatic data extraction from electronic patient records (EPRs), encrypted and sent to the Scientific Institute of Public Health $[28,29,36]$. The data collected cover the period from 1 June 2008 to 31 December 2011, enabling an observational retrospective cohort study.

\section{IMA pillar}

This pillar drew on the Intermutualistic Agency (IMA)'s administrative database of national compulsory health insurance data which includes data from all seven Belgian not-for-profit health insurance providers [37]. This database contains information on all reimbursed medications, medical and paramedical interventions and hospital admissions as well as socio-demographic data on all Belgian citizens who have health insurance. Data relevant to our research questions were collected covering the period between 1 January 2006 and 31 December 2010, enabling an observational retrospective cohort study. Data discussed in this article concerned frequency of measurement for HbA1c, LDL cholesterol, serum creatinine, number of encounters with selected care providers, prescription of

Table 1 Research domains and parameters under study for type 2 diabetes care trajectory (T2DM-CT). 1 September 2009 - 31 December 2011

\begin{tabular}{|c|c|c|}
\hline Research domains & Parameters studied & Target frequency/target value \\
\hline Recruitment of $C T$ patients & Number of enrolled patients & \\
\hline \multirow{8}{*}{$\begin{array}{l}\text { Mandatory parameters for all T2DM-CT } \\
\text { patients }\end{array}$} & \multirow[t]{2}{*}{$\mathrm{HbA1c}$} & Freq: every 3 months \\
\hline & & Target value: $<7 \%$ \\
\hline & \multirow[t]{2}{*}{ LDL cholesterol } & Freq: every 3 months \\
\hline & & Target value: $<100 \mathrm{mg} / \mathrm{dl}$ \\
\hline & \multirow[t]{2}{*}{ Blood pressure } & Freq: every 3 months \\
\hline & & Target value: $<130 / 80 \mathrm{mmHg}$ \\
\hline & \multirow[t]{2}{*}{ BMI } & Freq: every 3 months \\
\hline & & Target value: $<25 \mathrm{~kg} / \mathrm{m} 2$ \\
\hline \multirow[t]{3}{*}{ Disease review } & \multirow{2}{*}{$\begin{array}{l}\text { Number of encounters with selected care } \\
\text { providers }\end{array}$} & 2 encounters/year with GP \\
\hline & & 1 encounter/year with internist \\
\hline & Prescription of a glucometer & Number T2DM-CT patients with prescription of glucometer \\
\hline Primary revention & Flu vaccination & Annual flu vaccination \\
\hline \multirow[t]{4}{*}{$\begin{array}{l}\text { Complications/secundary and tertiary } \\
\text { prevention }\end{array}$} & Diabetes education & $\begin{array}{l}\text { At least } 1 \text { consultation with diabetes } \\
\text { educator/dietician }\end{array}$ \\
\hline & Renal function & Freq: Serum creatinine $1 \times /$ year \\
\hline & Statin use & All T2DM, except those without other cardiovascular risk factors \\
\hline & Ophthalmoscopy & Freq: $1 \times /$ year \\
\hline
\end{tabular}


glucometer, flu vaccination, consultations with diabetes educator and statin use.

\section{Intego registration network}

The Intego network, operational since 1997, is an EPRbased network of 54 voluntarily participating GP practices in Flanders, the northern region of the country, which all use the same EPR software [38]. The network is coordinated by the Academic Centre for General Practice at the Katholieke Universiteit Leuven. The network covers approximately $1.95 \%$ of the Flemish population. Information was extracted on all encounters and included individual demographic and administrative data, clinical and laboratory parameters, vaccinations and prescriptions.

The data used in this study covered the period between 1 January 2006 and 31 December 2011, enabling an observational retrospective cohort study. Data concerned frequency of measurement and values for HbA1c, LDL cholesterol, blood pressure, BMI, serum creatinine, flu vaccination and statin use.

\section{Sentinel network of general practices}

The Belgian Sentinel Network of General Practices (SGP), operational since 1979, is a paper-based nationwide network which collects data from approximately 140 voluntarily participating practices on a limited set of parameters related to specific health problems [39]. The network covers about $1.5 \%$ of the total Belgian population. Type 2 diabetes was among the themes recorded in 2010. Cross-sectional data concerned the three most recent values for HbA1c, blood pressure and weight, and the most recent value for height and LDL cholesterol.

\section{Data analysis}

Logistic and continuous multilevel analyses were carried out to study the effect of inclusion in the CT on achieving a care process or a health outcome target, controlling for potential confounders.
Triangulation of the four data sources was carried out [40], as each source has its own strengths and weaknesses [35].

This article examines data from the early phases of CT implementation and the years preceding the CT start. The data used covered the period from 2006 to 2011.

\section{Results}

Number of T2DM-CT patients and their basic characteristics

Table 2 describes the characteristics of the registered T2DM-CT cases by data source. The age and sex distributions and geographical spread of the four data sources were comparable.

A considerable number of patients were already enrolled in a CT in this early phase of CT implementation, as illustrated by the IMA and central pillar data.

\section{Patients' adherence with T2DM-CT obligations}

According to the CT care programme rules, every CT patient must have at least two encounters a year with his or her GP and one encounter a year with the internist. The IMA data indicate that $97 \%$ (95 \% CI: 96-97) of the CT patients had at least two encounters with their GP and $95 \%$ (95 \% CI: 94-95) had at least one encounter with the specialist in the year 2010.

\section{Patients' uptake of measures for T2DM-CT self-care}

The CT care programme facilitates self-monitoring of glucose through prescription and reimbursement of a glucometer. According to the IMA data, 50 \% (95 \% CI: 49-51) of the CT patients used this incentive in the period September 2009 - December 2010. The CT care programme also facilitates diabetes education by reimbursing consultations. According to the IMA data, 58 \% (95\% CI: 56-59) of the CT patients had at least one consultation with a diabetes educator or dietician in the period September 2009 - December 2010.

Table 2 Characteristics of type 2 diabetes care trajectory patients by data source. 1 September 2009 - 31 December 2011

\begin{tabular}{lllll}
\hline & Central pillar & IMA pillar & Intego & SGP \\
\hline Enrolment period & 1 Sept 2009-31 Dec 2011 & 1 Sept 2009-30 June 2010 & 1 Sept 2009- 31 Dec 2011 & $\begin{array}{l}\text { Cross-sectional data: } \\
\text { status on 31 Aug 2011 }\end{array}$ \\
Number of patients & 18250 & 8528 & 271 & 95 \\
Median study time & 15 months & 11 months & 13 months ${ }^{\mathrm{a}}$ & not applicable \\
Ratio of men:women & 1.08 & 1.03 & 1.08 & 0.79 \\
Median age(group) & $68 \mathrm{y}$ & $65-69 \mathrm{y}$ & $69 \mathrm{y}^{\mathrm{a}}$ & $67 \mathrm{y}$ \\
Geographic region & & & & $80 \%$ \\
Flanders & $83 \%$ & $89 \%$ & $100 \%$ & $13 \%$ \\
Wallonia & $13 \%$ & $9 \%$ & $0 \%$ & $7 \%$ \\
Brussels Region & $4 \%$ & $3 \%$ & $0 \%$ & \\
\hline
\end{tabular}

a Mean instead of median 


\section{Process of care for T2DM-CT patients prior, around and after CT start}

We observed a gradual improvement in the follow-up of CT patients' biological parameters, such as HbA1c and LDL cholesterol, and clinical parameters, such as blood pressure measurement, in the years before CT start (data not shown). However, the target frequency with which specific care processes should be carried out, had still not been attained for a considerable proportion of patients. This was the case, for instance, in the follow-up of ophthalmoscopy and flu vaccination, where according to the IMA data of 2008 only $33 \%$ (95\% CI: 32-34) of the patients had an ophthalmoscopy and 66 \% (95 \% CI: 65-67) have been vaccinated against flu.

On top of the improvement observed in the care processes during the years before $\mathrm{CT}$ start, we also saw a significant increase, around the start of the $\mathrm{CT}$, in the proportion of CT patients receiving adequate care (Table 3 ).

After this significant increase, the process parameters decreased slightly, but nevertheless remained at a higher level than prior to CT start.

The significant increase in frequency of T2DM-CT patient follow-up, we observed around the start of the CT, was far less notable among other T2DM patients (Fig. 1).

\section{Outcome of care for T2DM-patients prior and after CT start}

The T2DM-CT care programme recruited high-needs patients, who, according to the Intego network, prior to the start of the CT, had higher HbA1c levels, more rapidly declining renal function, and more diabetes-associated comorbidity compared to non-CT diabetic patients (Fig. 2).

CT patients were difficult to control in the years preceding the CT start. According to the SGP network, only $38 \%$ (95\% CI: $28-48$ ) of the CT patients had prior to the CT start a HbA1c value $<7 \%, 11 \%$ (95 \% CI: 5-18) had a blood pressure $<130 / 80 \mathrm{mmHg}$, and $8 \%$ (95 \% CI: 2-14) had a BMI $<25 \mathrm{~kg} / \mathrm{m}^{2}$. The proportion of CT

Table 3 Process of care parameters around the type 2 diabetes mellitus (T2DM) care trajectory (CT) start: degree of improvement in follow-up per trimester around individual CT start dates. IMA data, 2010, ACHIL project, Belgium

\begin{tabular}{lll}
\hline Process parameter & $\begin{array}{l}\text { Frequency of } \\
\text { measurement/year }\end{array}$ & $\begin{array}{l}\text { Improvement } 3 \text { months } \\
\text { before CT start }\end{array}$ \\
\hline HbA1C & $\geq 3$ & Odds ratio (per trimester) \\
LDL cholesterol & $\geq 1$ & $1.34^{*}$ \\
Serum creatinine & $\geq 1$ & $1.41^{*}$ \\
Ophtalmoscopy & $\geq 1$ & $1.42^{*}$ \\
Statines & $\geq 1$ prescription & $1.15^{*}$ \\
Flu vaccination & $\geq 1$ vaccination & $0.15^{*}$ \\
\hline
\end{tabular}

A value above 1 indicates an improvement in time per trimester. The symbol* after a value indicates that it is statistically significant, with $p<0.05$

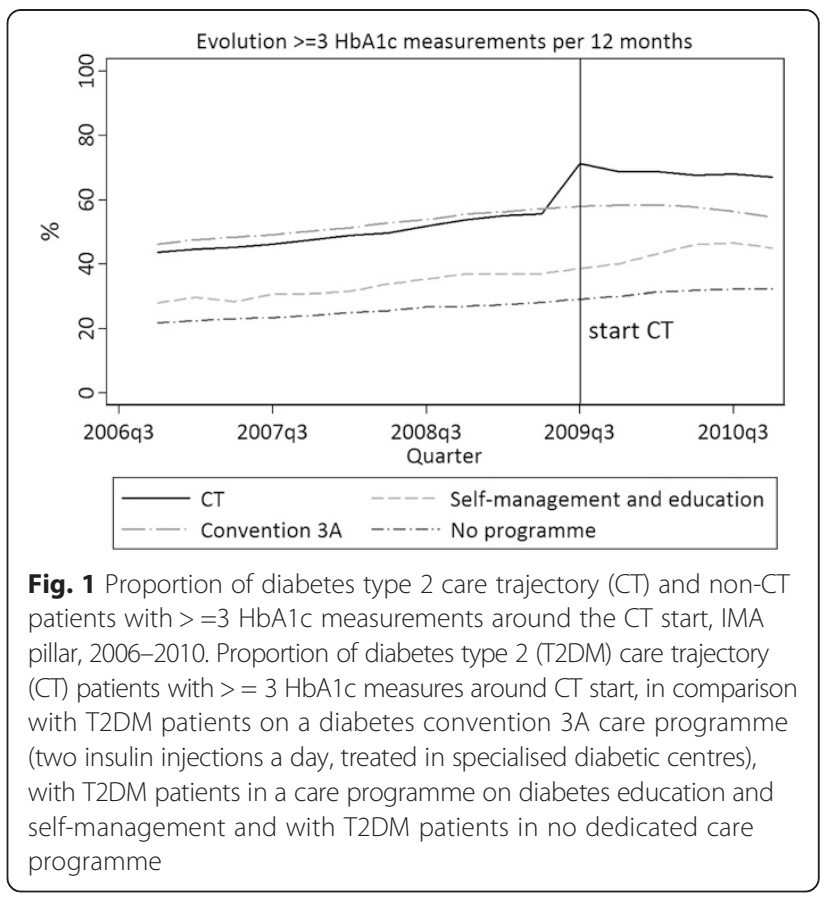

diabetics with an LDL cholesterol $<100 \mathrm{mg} / \mathrm{dl}$, on the other hand, was considerable (61 \%, $95 \%$ CI: 41-81). However, about two thirds of these patients were taking statins.

The central pillar data showed a significant decrease, after CT start, in HbA1c among three cohorts of T2DMCT patients, with CT start in 2009, 2010 and 2011, respectively (Fig. 3). This finding was confirmed by the Intego dataset [30]. According to the central pillar data, T2DMCT patients also experienced a significant decrease in LDL cholesterol, blood pressure and BMI after CT start (data not shown). However, these findings were not confirmed by the Intego dataset.

\section{Discussion}

This first phase of the ACHIL project aimed at studying the impact of the T2DM-CT care programme on quality of care, in terms of processes and outcomes, in the early period of the CT care programme implementation.

The focus was on quality of care in its narrowest sense (quality of technical care) in which practitioners' performance is measured by looking at its effectiveness to realize the achievable improvements in health status that have been made possible by the current science and technology of health care [41]. The assessment of quality of care in this study was limited to two levels: process (what is actually done in giving and receiving care), and outcome (effects of care on the health status of patients and populations). Other dimensions of quality of care, such as efficiency, patient and care providers satisfaction, were not dealt with in the ACHIL project. 


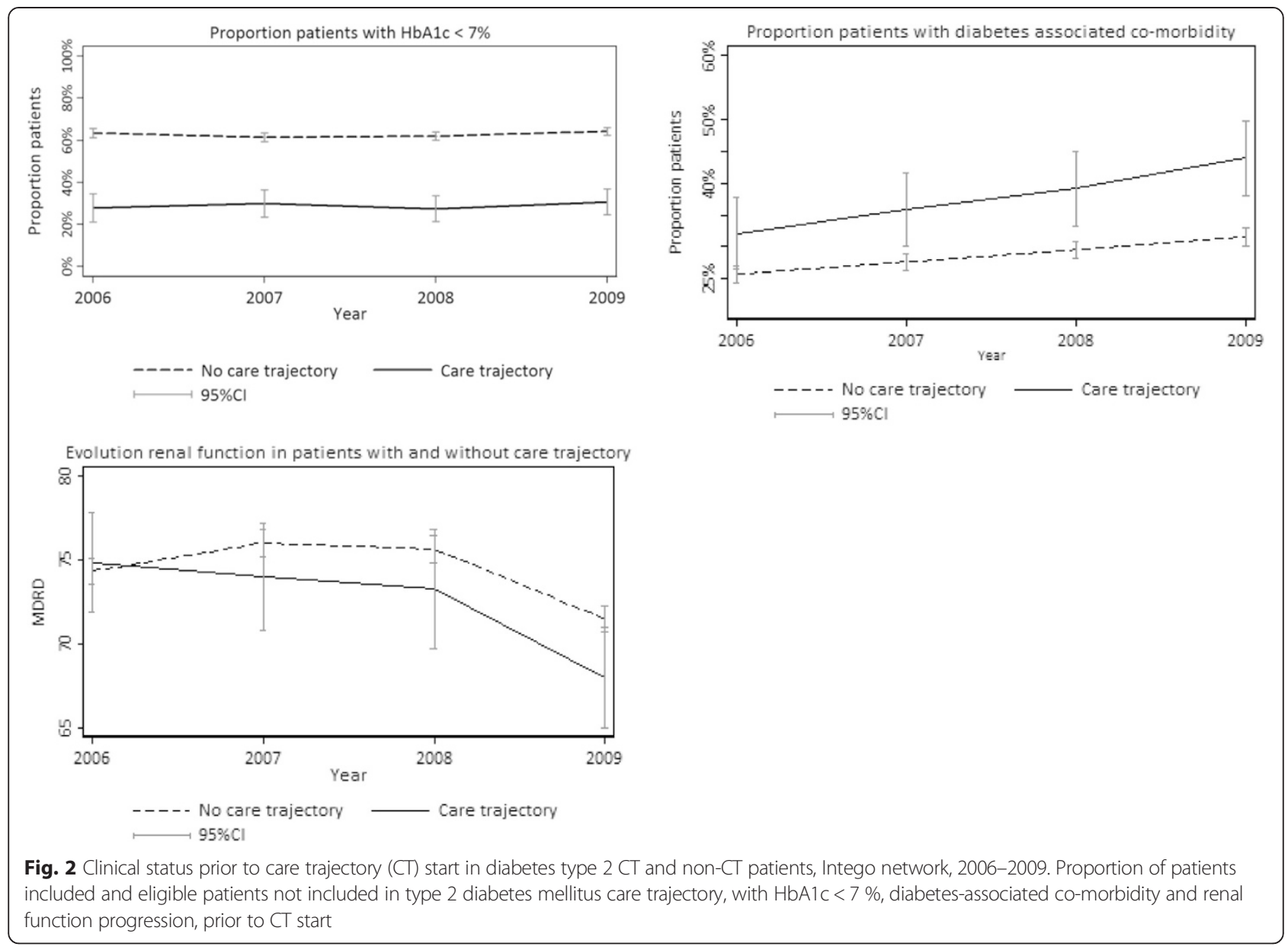

This study revealed that a considerable number of T2DM patients had already been enrolled in the early phase of the CT care programme implementation. More than $50 \%$ of the CT patients we studied were reimbursed for a glucometer. This care programme was effective in recruiting high-needs patients, who were difficult to supervise and had already undergone a more intensive follow-up prior to CT start. The vast majority of CT patients had the required number of encounters with their GP and the internist and more than $50 \%$ had at least one encounter a year with a diabetes educator or dietician. The CT care programme also proved to be effective in improving the follow-up of the patients enrolled, compared to both their own follow-up in the past and the follow-up of other diabetic patients. Despite the emergence of a number of positive trends, however, no conclusive results have yet been obtained in relation to health outcome parameters.

By 31 December 2011, the central pillar data-set had captured data on 18,250 T2DM-CT patients. Producing a reliable estimation of the number of patients eligible for a CT was impossible, however, due to the lack of data on the occurrence of the inclusion and exclusion criteria for a CT within the general population and the difficulty of obtaining reliable estimates of T2DM prevalence in Belgium. Nevertheless, the number of CT patients included in this study was considerable, and had increased to 46,561 by September 2014, according to recent NIHDI figures (NIHDI, personal communication).

According to the data provided by the Belgian Sentinel Network of General Practices (SGP), 16 \% (95 \% CI: 13-19) of all CT-eligible patients recorded by the network had been included in a CT by the end of the surveillance period in August 2011. The younger the CT-eligible patient, the more likely he or she was to be included in a CT. Patients living in Flanders (the northern region of the country) were more likely to have been included than were patients living in Wallonia (the southern region of the country). Motivated patients with specific plans to change their diet were also more likely to have been included in a CT. The most frequently reported reasons for non-inclusion, as mentioned by the GP, were the early timing of this study (inclusion was to take place in the near future) and inclusion in the diabetes convention 3A programme [31].

Despite the reimbursement facilities, consultations with diabetes educators did not occur as frequently as expected 


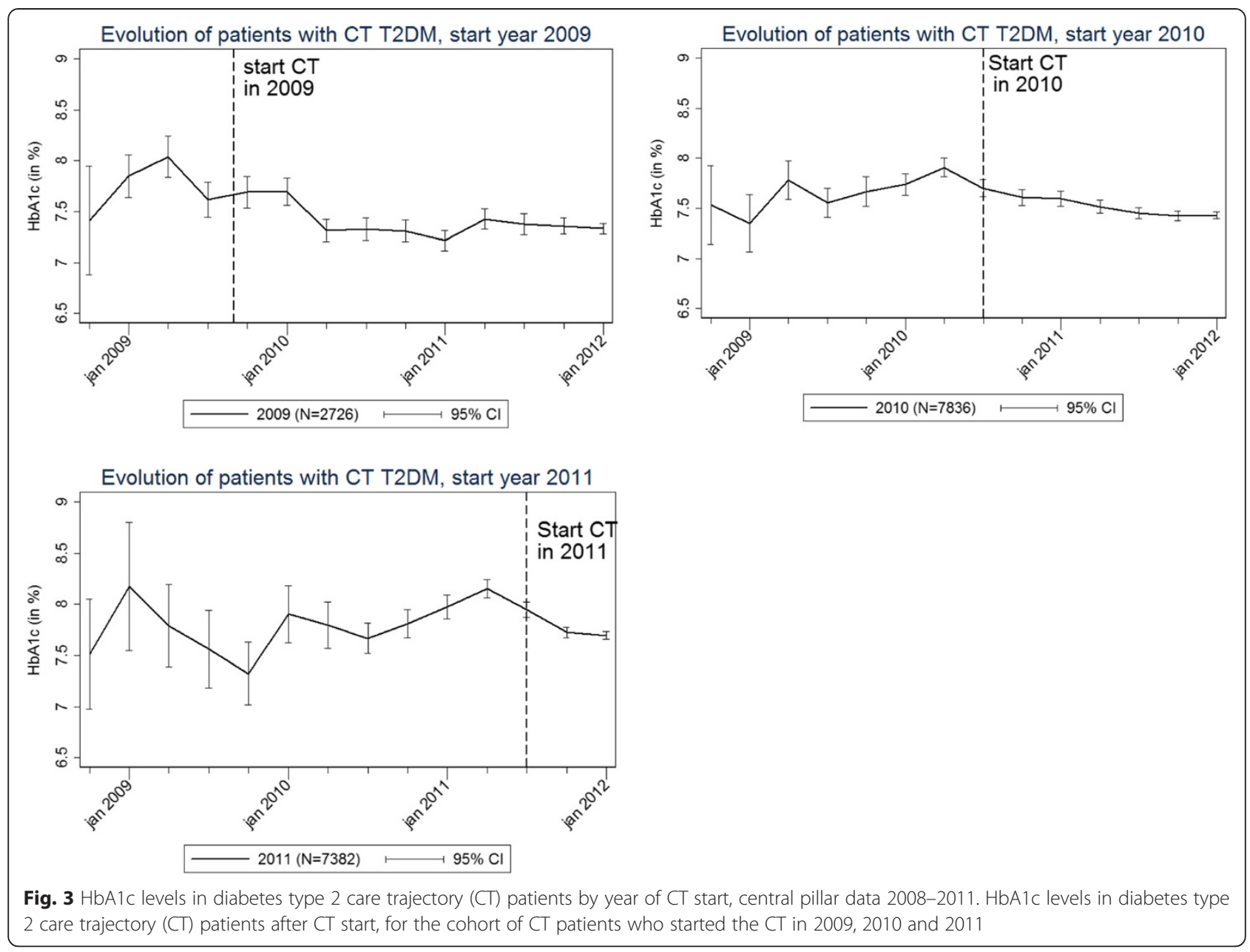

in this early phase of CT implementation. Several elements could have contributed to this underuse, such as the considerable administrative burden placed on GPs when making referrals to educators, the low financial compensation provided to educators, the insufficient amount of time allotted per education session, the lack of an accreditation system for diabetes educators, or patient factors other than financial incentives (e.g., perceived seriousness of the illness, external locus of control, low perceived self-efficacy, lack of social support,...).

The increased follow-up of various process parameters observed among T2DM-CT patients can be considered as an improvement in quality of care, as defined in evidencebased guidelines. For several of these process parameters, however, there is still considerable room for improvement. This is the case, for instance, for the yearly ophthalmoscopy exam, for which under $50 \%$ of the CT patients we studied conformed to the recommended frequency of follow-up.

Despite the emergence of a number of positive trends in health outcomes, no conclusive results have been obtained to date: a decrease in HbA1c, LDL cholesterol or blood pressure among T2DM-CT patients cannot necessarily be attributed to the CT programme. Additionally, an improvement in outcomes found in one data source was not always confirmed by another source. Any improvements in outcome were also rather small and it seems premature to consider them obvious improvements in a patient's health status (with slower disease progression as a result). Further research is needed to assess the trends in health outcomes due to the T2DM-CT.

The findings of this study corroborate with the evaluation results of other care programmes for chronic disease management in various countries in and outside Europe [9-20].

A criticism of the Belgian diabetes CT care programme is its focus on patients who already have advanced diabetes. While our results show that targeting this group of diabetics is justified, it is also known that the greatest benefit in terms of health and costs could be achieved by treating early-diagnosed patients well $[42,43]$. The need to extend this diabetes care programme has been recognised by the Belgian public health authorities and is presently under discussion. A second issue to be tackled is 
the present co-existence of the T2DM-CT and the diabetes convention 3A care programme, which to some extend target the same patients.

Another criticism of the Belgian CT care programme is the lack of a holistic approach. To date, two different CT programmes exist, one for T2DM and another for chronic renal failure. However, co-morbidity has not been taken into account in this approach, although the vast majority of elderly people have at least two chronic disorders. This criticism has also been recognised by the health authorities and therefore, the NIHDI recently established a working group on T2DM and multimorbidity.

This study has a number of limitations that should be acknowledged. The Belgian CT care programme is an example of a complex intervention, consisting of various elements: a contract, patient education measures, reimbursement of various consultations and self-control material, multidisciplinary local structures, and so on. The effectiveness studied here, concerns the CT care programme as a whole and not the individual elements.

The ACHIL project only focused on the effectiveness of the T2DM-CT programme in terms of quality of care processes and outcome. The CT being a complex intervention, it is likely that the participation of the patients and the effectiveness of the program not only depends on the program itself, but also, among other factors, on the patients' level of (health) literacy. The role of health literacy as a moderator of diabetes treatment effectiveness has been documented in the literature [44]. Besides, the same complexity could be a reason for the implementation fidelity of the program to be limited. Implementation fidelity in diabetes self-management programs is also mentioned as a potential mediating factor of effectiveness [45].

Another limitation of this study is that it concerns an observational study, which has a number of shortcomings compared to a randomised controlled study. Patients who were eligible for a CT, but not enrolled, were difficult to define in the data sources and, in addition, could not serve entirely as a control group for the CT patients. Besides this, the observation period was very short: no data were included after 2011, although the CT care programme started only in the summer of 2009. In the central data pillar, automatic extraction from EPRs appeared to be more promising than manual data entry. In 2012, however, only $9 \%$ of all CT patients' data were extracted from the EPR and many fields remained incomplete.

An important strength of this study is the fact that it involved the first large-scale (partly EPR-based) data collection, and included all GPs and CT patients. Another strength of the study is the use of triangulation between the four data sources. The conclusions of this study are based on congruent results obtained from the various data pillars, thus enforcing the validity of the conclusions and the validity of each data source individually. The framework of four different data sources developed here can be considered as an important basis for further evaluation of the effectiveness of the Belgian CT care programme.

\section{Conclusions}

In 2009, the NIHDI introduced care trajectories (CTs), a chronic disease management programme involving complex interventions. The evaluation of this programme's implementation is essential for the public health authorities. An important aspect of this evaluation consists of studying the effectiveness of the CT care programme with regard to the quality of care delivered and the outcome of care for patients. This study deals with this evaluation in the early phases of its implementation.

The ACHIL study found that, in the period 2009-2011, the CT care programme was effective in recruiting highneeds patients and in improving the processes of care for those patients. To date, however, no conclusive results have been obtained regarding the impact of the care programme on patient health outcomes.

As a result of this study, we recommend confirming the improvements found in care processes; further investigating patient health status outcomes and strengthening quality improvement by means of quality circles (plan-docheck-act). In order to achieve these recommendations, a longer observation period is needed, in combination with improved automatic data extraction from EPRs, monitoring of this improvement, linkage of data from EPRs with reimbursement data, extension of compulsory parameters in the central pillar and continuation of the triangulation between multiple data sources.

\section{Abbreviations}

ACHIL: Ambulatory Care Health Information Laboratory; BMI: Body mass index; CCM: Chronic care model; Cl: Confidence interval; CT: Care trajectory; EPR: Electronic patient record; GLP-analogues: Glucagon-like peptide analogues; GMF: Global Medical File; GP: General practitioner; HIS: Health Interview Survey; IMA: Intermutualistic Agency; KCE: Belgian Health Care Knowledge Centre; LDL: Low-density lipoprotein; NIHDI: National Institute for Health and Disability Insurance; SGP: Sentinel Network of General Practices; T1DM: Type 1 diabetes mellitus; T2DM: Type 2 diabetes mellitus.

\section{Competing interests}

There are no competing interests, financial or otherwise, to declare in relation to this manuscript.

\section{Authors' contributions}

WC was involved in the conception and design of the study, the acquisition of SGP data, the interpretation of the data from the four sources used and the drafting of the manuscript. NB participated in the conception and design of the study, the acquisition and analysis of the data from the IMA data source, the interpretation of the data from the four data sources used and the critical revision of the manuscript. SM participated in the conception and design of the study, the acquisition and analysis of the data from the central pillar data source, the interpretation of the data from the four data sources used and the critical revision of the manuscript. GG participated in the conception and design of the study, the acquisition and analysis of data from the Intego network, the interpretation of the data from the four data sources used and the critical revision of the manuscript. KVT participated in the conception and design of the study, the acquisition and analysis of data 
from the SGP network, the interpretation of the data from the four data sources used and the critical revision of the manuscript. JW participated in the development and selection of quality-related parameters for diabetes and the critical revision of the manuscript. EDC was involved in the conception and design of the study, the acquisition of the data from the central pillar data source, the interpretation of the data from the four data sources used and the critical revision of the manuscript. All authors read and approved the final manuscript.

\section{Acknowledgements}

This work was funded by the Belgian National Institute for Health and Disability Insurance (NIHDI).

\section{Author details}

${ }^{1}$ Scientific Institute of Public Health, Operational Direction Public Health and Surveillance, J. Wytsmanstreet 14, 1050 Brussels, Belgium. ${ }^{2}$ Katholieke Universiteit Leuven - Academisch Centrum voor Huisartsgeneeskunde, Kapucijnevoer 33 Blok J Bus 7001, 3000 Leuven, Belgium. ${ }^{3}$ UZ Leuven - MIR (Management Informatie Rapportering, Herestraat 49, 3000 Leuven, Belgium. ${ }^{4}$ Vrije Universiteit Brussel, Demografie, Pleinlaan 2, 1050 Brussel, Belgium. ${ }^{5}$ Universiteit Antwerpen, Academisch Centrum voor Huisartsgeneeskunde, Campus 3 Eiken, Universiteitsplein 1, 2610 Wilrijk, Belgium. 'Université Catholique de Louvain, Institut de Recherche Santé et Société, Clos Chapelle aux Champs 30, 1200 Brussels, Belgium.

Received: 2 March 2015 Accepted: 5 May 2015

Published online: 13 July 2015

\section{References}

1. Van Der Heyden J. Contacts avec le médecin généraliste. In: Drieskens $S$, Gisle L, editors. Enquête de santé 2013. Rapport 3 : Utilisation des services de soins de santé et des services sociaux. Bruxelles: WIV-ISP; 2015. p. 31-67.

2. Debacker $N$, Nobels F, Vandenberghe H, Van Combrugge P, Scheen A, Van Casteren V. Organization of a quality-assurance project in all Belgian multidisciplinary diabetes centres treating insulin-treated diabetes patients: 5 years' experience. Diabet Med. 2008;25(2):179-85.

3. Doggen K, Nobels F, Scheen AJL, Van Combrugge P, Van Casteren V, Mathieu C. Cardiovascular risk factors and complications associated with albuminuria and impaired renal function in insulin-treated diabetes. J Diab Compl. 2013;27:370-5.

4. Doggen K, Van Acker K, Beele H, Dumont I, Félix P, Lauwers P, et al. Implementation of a quality improvement initiative in Belgian diabetic foot clinics: feasibility and initial results. Diabetes Metab Res Rev. 2014;30:435-43.

5. Van Der Heyden J. Maladies chroniques. In: Van Der Heyden J, Charafeddine R, editors. Enquête de santé 2013. Rapport 1 : Santé et Bien-être. Bruxelles: WIV-ISP; 2014. p. 63-225.

6. Goderis G, Borgermans L, Heyrman J, Van Den Broeke C, Grol R, Boland B, et al. Type 2 diabetes in primary care in Belgium: need for structured shared care. Exp Clin Endocrinol Diabetes. 2009;117:367-72.

7. Goderis G, Borgermans L, Grol R, Van Den Broeke C, Boland B, Verbeke G, et al. Start improving the quality of care for people with type 2 diabetes through a general practice support program: a cluster randomized trial. Diabetes Res Clin Pract. 2010:88:56-64.

8. Mathieu C, Nobels F, Peeters G, Van Royen P, Dirven K, Wens J, et al. De kwaliteit en organisatie van type 2 diabeteszorg. Brussel: KCE; 2006.

9. Boyle PJ, O'Neil KW, Berry CA, Stowell SA, Miller SC. Improving diabetes care and patient outcomes in skilled-care communities: successes and lessons from a quality improvement initiative. J Am Med Dir Assoc. 2013;14:340-4.

10. Campbell DJ, Sargious P, Lewanczuk R, McBrien K, Tonelli M, Hemmelgarn B, et al. Use of chronic disease management programs for diabetes: in Alberta's primary care networks. Can Fam Physician. 2013;59:e86-92.

11. Coelho A, Leone C, Ribeiro V, Sa MP, Dussault G. Integrated disease management: a critical review of foreign and Portuguese experience. Acta Med Port. 2014;27:116-25.

12. Gress S, Baan CA, Calnan M, Dedeu T, Groenewegen P, Howson H, et al. Co-ordination and management of chronic conditions in Europe: the role of primary care-position paper of the european forum for primary care. Qual Prim Care. 2009:17:75-86.

13. Halladay JR, Dewalt DA, Wise A, Qaqish B, Reiter K, Lee SY, et al. More extensive implementation of the chronic care model is associated with better lipid control in diabetes. J Am Board Fam Med. 2014;27:34-41.
14. Hamar GB, Rula EY, Wells A, Coberley C, Pope JE, Larkin S. Impact of a chronic disease management program on hospital admissions and readmissions in an Australian population with heart disease or diabetes. Popul Health Manag. 2013;16:125-31.

15. Katz I, Schneider H, Shezi Z, Mdleleni G, Gerntholtz T, Butler O, et al. Managing type 2 diabetes in Soweto-the south African chronic disease outreach program experience. Prim Care Diabetes. 2009;3:157-64.

16. Knai C, Nolte E, Brunn M, Elissen A, Conklin A, Pedersen JP, et al. Reported barriers to evaluation in chronic care: Experiences in six European countries. Health Policy. 2013;110:220-8.

17. Nagel H, Baehring T, Scherbaum WA. Implementing disease management programs for type 2 diabetes in Germany. Manag Care. 2006;15:50-3.

18. Nolte E, Knai C, Hofmarcher M, Conklin A, Erler A, Elissen A, et al. Overcoming fragmentation in health care: chronic care in Austria, Germany and The Netherlands. Health Econ Policy Law. 2012;7:125-46.

19. Rosenzweig JL, Taitel MS, Norman GK, Moore TJ, Turenne W, Tang P. Diabetes disease management in Medicare Advantage reduces hospitalizations and costs. Am J Manag Care. 2010;16:e157-62

20. Schafer I, Kuver C, Gedrose B, Hoffmann F, Russ-Thiel B, Brose HP, et al. The disease management program for type 2 diabetes in Germany enhances process quality of diabetes care - a follow-up survey of patient's experiences. BMC Health Serv Res. 2010;10:55.

21. Bodenheimer $T$, Wagner $E H$, Grumbach K. Improving primary care for patients with chronic illness: the chronic care model, Part 2. JAMA. 2002;288:1909-14.

22. Bodenheimer T, Wagner EH, Grumbach K. Improving primary care for patients with chronic illness. JAMA. 2002;288:1775-9.

23. Wagner EH, Austin BT, Von Korff M. Organizing care for patients with chronic illness. Milbank Q. 1996;74:511-44.

24. Wagner EH. Chronic disease management: what will it take to improve care for chronic illness? Eff Clin Pract. 1998;1:2-4

25. Wagner EH, Austin BT, Davis C, Hindmarsh M, Schaefer J, Bonomi A. Improving chronic illness care: translating evidence into action. Health Aff (Millwood). 2001;20:64-78.

26. RIZIV-INAMI Zorgtrajecten - Trajets de soins. [http://www.zorgtraject.be/NL/ index.asp],[http://www.trajetdesoins.be/FR/index.asp]

27. Bossuyt N, Van Casteren V, Goderis G, Wens J, Moreels S, Vanthomme K, et al. Public Health Triangulation to inform decision-making in Belgium. In Proceedings of the 26th Medical Informatics Europe Conference:27-29 May 2015; Madrid. (in press).

28. De Clercq E, Van Casteren V, Bossuyt N, Goderis G, Moreels S. Belgian primary care EPR: assessment of nationwide routine data extraction. Stud Health Technol Inform. 2014;197:85-9.

29. De Clercq E, Van Casteren V, Bossuyt N, Goderis G, Moreels S. EPR-based, quality-related process parameters: a nationwide assessment. Stud Health Technol Inform. 2014:205:121-5.

30. Goderis G, Van Casteren V, De Clercq E, Bossuyt N, Van den Broecke C, Vanthomme $\mathrm{K}$, et al. Care trajectories are associated with quality improvement in the treatment of patients with uncontrolled type 2 diabetes: a registry based cohort study. Prim Care Diab. 2015;http:// dx.doi.org/10.1016/j.pcd.2015.01.008

31. Vanthomme K, Bossuyt N, Moreels S, Boffin N, De Clercq E, Goderis G, et al. What determines inclusion in the early phase of the type 2 diabetes care trajectory in Belgium? Archives of Public Health. 2014;72:29.

32. Wens J, Sunaert $P$, Nobels F, Feyen L, Van Crombruggen $P$, Bastiaens $H$, et al. Aanbeveling voor goede medische praktijkvoering: Diabetes Mellitus type 2. Domus Medica: Berchem/Gent; 2005.

33. Ceuppens A, Corveleyn T, Degauquier K, Vandermeersch G, Vanoverloop J, Widera I. De diabetes conventie. Brussel: IMA-AIM; 2005

34. Sunaert $P$, Bastiaens $H$, Nobels F, Feyen L, Verbeke G, Vermeire E, et al. Effectiveness of the introduction of a chronic care model-based program for type 2 diabetes in Belgium. BMC Health Serv Res. 2010;10:207.

35. Van Casteren V, Bossuyt N, Moreels S, Vanthomme K, Goderis G, De Clercq E. De zorgtrajecten diabetes mellitus type 2 en chronische nierinsufficiëntie: impact op de kwaliteit van zorg. Brussel: WIV-ISP; 2013.

36. De Clercq E, Van Casteren V, Bossuyt N, Moreels S, Goderis G, Bartholomeeusen S, et al. Nation-wide primary healthcare research network: a privacy protection assessment. Stud Health Technol Inform. 2012;174:23-8.

37. IMA-AIM.[http://www.nic-ima.be/nl/imaweb/home/index.html], [http:// www.nic-ima.be/fr/imaweb/home/index.html]

38. Truyers C, Goderis G, Dewitte H, Vanden Akker M, Buntinx F. The Intego database: background, methods and basic results of a Flemish general 
practice-based continuous morbidity registration project. BMC Med Inform Decis Mak. 2014;14:48.

39. Lobet MP, Stroobant A, Mertens R, Van Casteren V, Walckiers D, Masuy-Stroobant G, et al. Tool for validation of the network of sentinel general practitioners in the Belgian health care system. Int J Epidemiol. 1987;16:612-8

40. World Health Organization. HIV triangulation resource guide: synthesis of results from multiple data sources for evaluation and decision-making. Geneva: World Health Organization; 2009.

41. Donabedian A. The quality of care. How can it be assessed? JAMA 1988;23:1743-8.

42. Bailey CJ, Del Patro S, Eddy D, Zinman B. Earlier intervention in type 2 diabetes: the case for achieving early and sustained glycaemic control. Int J Clin Pract. 2005;59:1309-16.

43. Holman RR, Paul SK, Bethel MA, Matthews DR, Neil HA. 10-year follow-up of intensive glucose control in type 2 diabetes. N Engl J Med. 2008;359:1577-89.

44. Schillinger D, Barton LR, Karter AJ, Wang F, Adler N. Does literacy mediate the relationship between education and health outcomes? A study of a low-income population with diabetes. Public Health Rep. 2006;121(3):245-54

45. Schinckus L, Van den Broucke $S$, Housiaux M. Assessment of implementation fidelity in diabetes self-management education programs: a systematic review. Patient Educ Couns. 2014;96(1):13-21.

\section{Submit your next manuscript to BioMed Central and take full advantage of:}

- Convenient online submission

- Thorough peer review

- No space constraints or color figure charges

- Immediate publication on acceptance

- Inclusion in PubMed, CAS, Scopus and Google Scholar

- Research which is freely available for redistribution 